
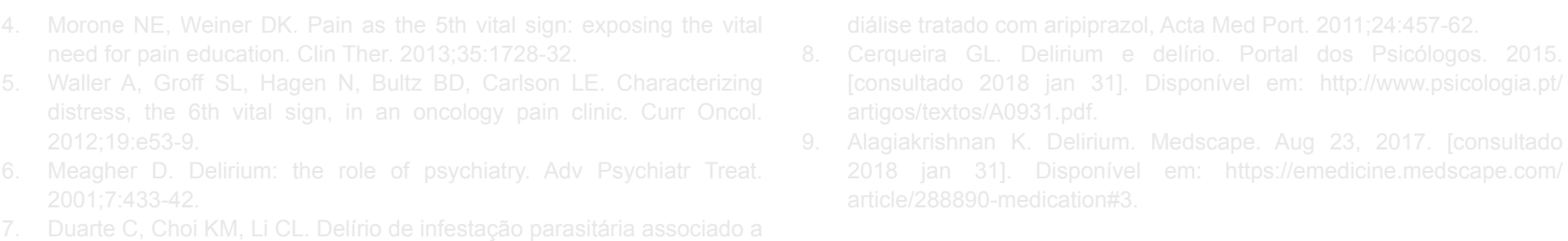

\section{Resposta a Carta ao Editor: Ainda a Propósito do Delirium}

\section{Reply to the Letter to the Editor: Still About Delirium}

Palavras-chave: Cuidados Paliativos; Delírio Keywords: Cost of Illness; Delirium

\section{Caro Colega,}

Foi com grande satisfação que lemos os seus comentários a respeito do artigo que publicámos e agradecemos o interesse demonstrado, pois este tema é de facto da maior pertinência e carece de maior informação e formação por parte dos diversos profissionais de saúde.

Quanto aos esclarecimentos solicitados:

1. É comumente aceite que os quatro sinais vitais são a pressão arterial, a frequência cardíaca (por vezes indevidamente substituída pela frequência de pulso), a frequência respiratória e a temperatura. Um quinto sinal vital, a dor, foi proposto pelo médico James Campbell em 1995, sendo atualmente aceite pelo Veterans Health Administration (VHA) e o Joint Commission on Accreditation of Healthcare Organizations, ${ }^{1}$ e utilizado por profissionais de saúde a nível global. Quando se procura um sexto sinal vital na literatura, deparamo-nos com uma miríade de propostas, incluindo o distress, ${ }^{2}$ o distress/sofrimento emocional, ${ }^{3}$ a velocidade de caminha-

\section{REFERÊNCIAS}

1. Morone N, Weiner D. Pain as the fifth vital sign: exposing the vital need for pain education. Clin Ther. 2013;35:1728-32.

2. Howell D, Olsen K. Distress - the 6th vital sign. Curr Oncol. 2011;18.

3. Bultz B, Carlson L. Emotional distress: the sixth vital sign in cancer care. J Clin Oncol. 2005;23:6440-1.

4. Fritz S, Lusardi M. White paper: "walking speed: the sixth vital sign". J Geriatr Phys Ther. 2009;32:2-5.

5. Flaherty JH, Rudolph J, Shay K, Kamholz B, Boockvar KS, Shaughnessy $M$, et al. Delirium is a serious and under-recognized problem: why assessment of mental status should be the sixth vital sign. J Am Med Dir Assoc. 2007;8:273-5.

6. Rosenow E. Patients' understanding of and compliance with medications: the sixth vital sign?. Mayo Clin Proc. 2005;80:983-7.

7. Heinrich $C$. Health literacy: the sixth vital sign. J Am Acad Nurse Pract. 2012;24:218-23.

8. Hunter C, Silvestri S, Ralls G, Bright S, Papa L. The sixth vital sign: da, ${ }^{4}$ o próprio delirium, ${ }^{5}$ a adesão terapêutica, ${ }^{6}$ a alfabetização na saúde, ${ }^{7}$ a concentração de $\mathrm{CO}_{2}$ no final da expiração (ETCO2), ${ }^{8}$ o trânsito intestinal, ${ }^{9}$ a continência urinária,$^{10} \mathrm{o}$ risco de queda ${ }^{11} \mathrm{e}$ o status funcional. ${ }^{12}$ Estas numerosas propostas pretendem, do ponto de vista destes autores, alertar os profissionais de saúde para tópicos de elevada relevância e impacto no cuidado aos doentes e é essa a lógica por base na nossa proposta de designar o delirium como um sinal vital. Pela ausência de concordância no que será o sexto sinal vital, as autoras propõem o delirium como o sétimo sinal vital, evitando ampliar a desordem associada ao sinal prévio e porque consideram o delirium como merecedor de reconhecimento e subsequente abordagem, de forma universal.

2. e 3. Entre a extensão do tema, sem dúvida estes são dois aspetos pertinentes. Efetivamente a nomenclatura na área do delirium é diversa e heterogénea, existindo diversos sinónimos e por vezes o uso incorreto por confusão com o termo delírio como assinalou. Os autores destacaram apenas o termo mais frequentemente usado como sinónimo - síndrome ou estado confusional agudo, mas na literatura termos como agitação, alteração da consciência, encefalopatia, falência cerebral aguda, síndrome cerebral agudo, psicose são aplicados a áreas específicas como os Cuidados Intensivos, Cuidados Paliativos ou áreas Cirúrgicas. ${ }^{12,13}$

prehospital end-tidal carbon dioxide predicts in-hospital mortality and metabolic disturbances. Am J Emerg Med. 2014;32:160-5.

9. Dedeli O, Pakyuz S. Bowel movement: the sixth vital sign?. Clin Exp Health Sci. 2016;6:135-9.

10. Joseph A. Continence: the sixth vital sign?. Am J Nurs. 2003;103:11.

11. Younce A, Hinton D, Haynes D, Berg J. Make fall risk the sixth vital sign. Nursing. 2011;41:62-4.

12. May C. Chronic illness and intractability: professional - patient interactions in primary care. Chronic IIIn. 2005;1:15-20.

13. Lipowski ZJ. Delirium (acute confusional states). JAMA 1987;258:178992.

14. Morandi A, Pandharipande P, Trabucchi M, Rozzini R, Mistraletti $\mathrm{G}$, Trompeo AC, et al. Understanding international differences in terminology for delirium and other types of acute brain dysfunction in critically ill patients. Intensive Care Med. 2008;34:1907-15. 
Filipa QUARESMA $\triangle^{1}$

1. Unidade Funcional Medicina 1.2. Centro Hospitalar de Lisboa Central. Lisboa. Portugal.

Autor correspondente: Filipa Quaresma. fquaresma15@gmail.com

Recebido: 04 de fevereiro de 2018 - Aceite: 09 de fevereiro de 2018 | Copyright @ Ordem dos Médicos 2018

https://doi.org/10.20344/amp.10386 